\title{
Examining the Psychological Health Quality of Life of Older People with Disability in Selected Districts in Ghana
}

\author{
Bismark Nantom ah ${ }^{1}$, Elijah Yendaw ${ }^{2}$, Frank M. Borbor ${ }^{3}$ and Kwadwo Asante-Afari ${ }^{4}$ \\ 1Department of Integrated Social Sciences, Ghana Institute \\ of Journalism, P. O. Box GP 667, Accra, Ghana. \\ Email: nantomahbismark@yahoo.com; Tel: +233-207707226 \\ 2Department of Governance and Development Management, \\ Faculty of Public Policy and Governance, SD Dombo University of \\ Business and Integrated Development Studies, Wa, Ghana. \\ Email: eyendaw@uds.edu.gh; Tel: +233-554 052799 \\ 3DBS Industrial LTD, Shai Hills, Afienya. Email: borbormawutor@ \\ yahoo.com, Tel: +233-244702449 \\ 4 Health Promotion Division, Ghana Health Service, Accra, Ghana. \\ Email: akwadwo2003@yahoo.com;Tel: +233-200267796 \\ Corresponding Author: Bismark Nantomah1: Email: nantomahbismark@ \\ yahoo.com; Tel: $+233-207707226$
}

CONFLICT OF INTEREST: The authors declare that there are no conflicts of interests.

\section{ACKNOWLEDGEMENTS}

This paper was extracted from a thesis submitted to the School of Graduate Studies of the University of Cape Coast, Ghana. It is important to acknowledge the World Health Organization for permitting the adaptation of the WHOQOL-BREF questionnaire for this study. Also, it is substantial to highlight the diverse contributions of the Assembly men and women, field assistants and older people with disability in the study.

DOI//http://dx.doi.org/10.4314/gjds.v18i2.4

\section{ABSTRACT}

Older people in Ghana suffer from a wide range of disabilities including visual, physical, and hearing with serious ramifications on their quality of life. Therefore, this paper examines the psychological health quality of life (PHQOL) of older people with disability in selected Districts in the Upper West Region of Ghana. Through a census survey, questionnaires were used to obtain data from 810 respondents. 
Independent-samples t-test and one-way Analysis of Variance (ANOVA) were used to examine their PHQOL. The results showed that mean scores in PHQOL were highest among those aged 60-69 and lowest for those aged 80 years and older with a significant difference $[F(807)=23.872$ value, $p=0.000]$ in $\mathrm{PHQOL}$ of their ages. Those who were married had the highest $\mathrm{PHQOL}$ mean score compared with those who were separated / divorced and widowed with significant difference [F $(807)=42.690$ value, $p=0.000$ ] noticed in PHQOL across marital statuses. Also, those with physical disability had a higher mean score in PHQOL than those with visual disability. The study concludes that any geriatric policy interventions aimed at improving the PHQOL of older people with disability ought not to downplay their background characteristics as they underpin their PHQOL. KEY WORDS: Aged, Disability, Older people with disability, Psychological health quality of life, Quality of life.

\section{INTRODUCTION}

Though life expectancy is increasing, a substantial proportion of older people (aged population) are battling with disability (World Health Organization [WHO], 2014a). Disability of individuals can range from mild to severe and whether a person is considered to have a disability is highly dependent on their economic, physical, cultural and legal environments (WHO, 2002a; Braithwaite \& Mont, 2009). The economic model of disability suggests that population ageing brings about the demand for special goods and services by older people with disability (Jongbloed, 2003; Travability, 2011). This model points out that disability generally leads to greater medical and care giving expenses, and in some cases, these expenses are unbearable (Cutler et al., 2009). In the World at large, sensory declines including visual and physical impairments are a broad category of normal age-related changes that often lead to loss of independence and eventually diminishes the quality of life (QOL) of older people (WHO, 2011; WHO, 2014a). That is why $\mathrm{QOL}$ is viewed as a broad concept incorporating a person's physical health, psychological state, level of independence, social relationships, personal beliefs and environmental factors that affect him or her (WHO, 2002b; WHO, 2011). Despite the broad nature of $\mathrm{QOL}$, psychological health $\mathrm{QOL}(\mathrm{PHQOL})$ is the satisfaction individuals derive when their psychological needs are met (Kerce, 1992; Tsakiri, 2010). Also, $\mathrm{PHQOL}$ is perceived as the mental state where the individual considers that his or her material and social needs are fulfilled (Davidson et al., 2017). The PHQOL of older people unlike younger people is greatly affected as ageing sets in with its associated disability (WHO, 2014a). 
Even though ageing is associated with a higher risk of disability, it does not prevent the population from ageing (WHO, 2011; WHO, 2014a). For instance, in Ghana, the population of older people increased from 213,477 in 1960 to 1,643,381 in 2010 constituting 4.5 and 6.7 percents of the total national populations respectively (Ghana Statistical Service [GSS], 2013a). This increasing proportion of older people in the population presents challenges to policy makers, families, non-governmental organisations, religious bodies and health care providers to meet the $\mathrm{QOL}$ needs of the ageing individuals (Smith, 2000; Velkoff \& Kowal, 2007).

QOL research of older people has become an important issue because of demographic changes resulting from the ageing of the population (Cao et al., 2016). Ba-Ama and YaabaAckah (2014) revealed that migration, economic pressure and urbanisation have caused children to stay far away from their aged parents in Ghana. Also, Mba (2007) and GSS (2012) suggest that the probability of solitary living, and hence the need for support and care, is more pronounced among the elderly from the Northern, Upper West and Upper East Regions of Ghana. Further, Ayernor (2012) research on diseases of ageing in Ghana discovered that having a chronic non-communicable condition of those who lived in a rural area is twice as likely as those who reside in an urban area. Although some studies have been conducted on older people in Ghana, there are few data available on the PHQOL of older people with disability. In the Upper West Region in particular, no systematic empirical work has been undertaken on this important subject. In an attempt to fill this lacuna in the literature, the current study examined the PHQOL of older people with disability in selected Districts in the Upper West Region of Ghana (Wa Municipality, NadowliKaleo, Jirapa and Wa East Districts).

In order to make the study more focused and easier to comprehend by the general readership, it was guided by this research question: How do socio-demographic characteristics of older people with disability determine their psychological health QOL? This study is distinct and timely for two reasons. One, it is the first to have used the WHOQOL-BREF questionnaire in examining the PHQOL of older people with disability in Ghana; and two, it could enhance discussions on policy direction on the PHQOL of older people with disability especially in this era of the COVID-19. The study is organized under six thematic areas: Introduction, conceptual and theoretical perspectives, methods, results, discussion, and conclusions and implications. 


\section{CONCEPTUAL AND THEORETICAL PERSPECTIVES}

Ageing, disability, and psychological health QOL have been of concern to many scholars across the world (Schalock et al., 2002; Giddens et al., 2005). In the available literature, the term ageing has been conceptualised differently (Kinsella \& Phillips, 2005). In one perspective, ageing is described as a normal biological process, which involves the loss of cell or organ physiological functions and inability to perform physical activity (Aydos, 2012). In another view, ageing means declining psychological health QOL, reduced physical ability and the onset of disability (Weeks, 1999; Dubey et al., 2011). Theoretically however, the Hayflick limit theory posits that ageing is a biological process which is controlled by a biological clock contained within each living cell (Hayflick \& Moorehead, 1980; Jin, 2010). Parallel to the Hayflick limit theory, the modernisation theory views the concept of ageing as a period where the status, knowledge, traits and skills of older people are deemed less relevant or less valuable as society becomes more civilized (Kinsella \& Phillips, 2005). Adding to these multiple perspectives on ageing, the disengagement theory argues that ageing is the mutual withdrawal of the individual from life roles at the point where his or her productivity declines (Putnam, 2002).

Equally, the concept of disability has no single definition (HelpAge International, 2004; WHO, 2011). It is conceived as an individual's inability to do certain things, as a result of partial or total loss of a physical function including seeing, hearing, talking and movement (HelpAge International, 2004; WHO, 2014b). In another vein, it is a limitation in performing tasks, activities, and roles at expected levels in the physical and social spheres of life (Mann, 2004). However, this study targets older persons with visual and physical disability. In this regard, visual disability depicts a limitation in the performance of an individual's sight due to loss of function of the eye (s) because of impairment or malformation (WHO, 2011; GSS, 2012). In contrast, physical disability is a limitation in the performance of an individual's motor skills due to loss of function of either/or the neck, hand, arm, waist, leg and knee as a consequence of impairment, malformation or accident (Castañer et al., 2009; GSS, 2012). The motor skills of an individual according to Castañer et al. (2009) are actions that involve movements of his or her arms, legs, feet, or the entire body.

Moreover, divergent views have been held by scholars about the concept of PHQOL (Schalock et al., 2002; Murphy et al., 2007). It is considered as an accumulated experience of feelings of joy, pleasure, contentment, and life satisfaction (Diener \& Suh, 1997; Tripathi, 2012). Also, PHQOL is described as individuals' personal evaluation about their experiences of emotional tension, depression, anxiety, social 
skills and skills to cope with adverse situations (Goldberg et al., 1997). In another view, it is the subjective interpretation made by individuals about their life which affects their emotional adjustment (Gómez, Gutiérrez, Castellanos, Vergara, Pradilla, 2010). However, this study aligns to the perspective that PHQOL is the perception individuals have about their life enjoyment, meaningfulness of life, concentration, bodily image, self-esteem, and negative feelings (WHO, 1996; World Health Organization Quality of Life [WHOQOL] Group, 1997).

Generally, the WHO (1996) identifies four main domains of QOL including physical health, psychological health, social relations and environmental health. However, for the purpose of this study, the interaction between the determinants of PHQOL framework (Figure 1) is used. This framework is adapted from the International Classification of Functioning, Disability and Health (ICF) model (WHO, 1996; WHO, 2001). Though there are other models of disability, the ICF model is most relevant to this study in many ways. It provides a standard and unified framework for measuring and describing not only the concept of QOL of individuals in a real-life situation, but also in identifying ways of intervening with the right policies to improving the life situations of individuals with disabilities (WHO, 2001; Schalock, 2004; Saleeby, 2007). Again, the model presents a complex bio-psychosocial approach which can be used in describing how people with disabilities (PWDs) are participating in society as required by the UN Convention on the Rights of PWDs (Clarke \& Nieuwenhuijsen, 2009; WHO, 2013). In addition, it has internal ethical guidelines which are in line with the principles of the UN Convention (WHO, 2013). 


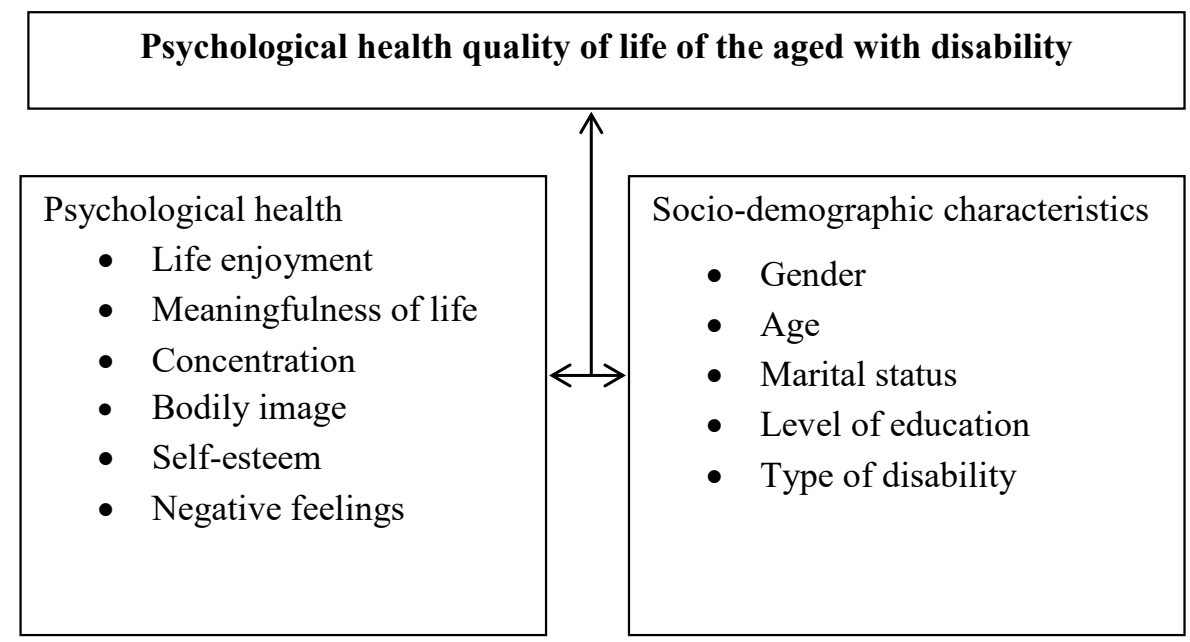

Figure 1: Interaction between the determinants of psychological health QOL framework Source: Adapted from $\mathrm{WHO}$ (1996) and WHO (2001).

From Figure 1, the PHQOL of older people with disability is determined by the interaction of psychological health and socio-demographic characteristics domains (WHO, 1996). Each of these two domains has other subcomponents which interact in an intra and inter-symbiotic manner in determining the PHQOL of older people with disability (WHO, 1996).

The psychological health domain constitutes life enjoyment, meaningfulness of life, concentration, bodily image, self-esteem, and negative feelings. Life enjoyment relates to how much satisfaction an individual perceives to enjoy from his / her physical, social, economic, political, and spiritual environment (WHO, 1996). Meaningfulness of life is a central resource of an individual in self-regulation and self-perception, which support the use of adaptive behaviours and offer a feeling of existential meaning (Damasio, de Melo, \& da Silva, 2013). Concentration could be defined as the mental ability of an individual's mind which focuses on a single object without interruption (Grewal, 2014). Bodily image concerns the amount of satisfaction or dissatisfaction individuals feel about their body or body parts (Bailey, Gammagea, \& van Ingena, 2017). Self-esteem is the way in which people feel about themselves in relation to their social standing, ethnic group, physical features, or performance (Abdel-Khalek, 2016). Negative feelings relate to the dissatisfaction individuals feel about their body or body parts (Bailey et al., 2017). 
In the family setting for instance, visual disability of older people mostly requires a renegotiation of their basic activities of daily living such as bathing, dressing, housekeeping, and running errands which adversely affect their PHQOL (Brown \& Barrett, 2011). In line with the above observations in the literature, the study hypothesised that the socio-demographic characteristics (gender, age, marital status, level of education and type of disability) of older people with disability have no significant effect on their PHQOL (Figure 1).

\section{METHODS}

\section{Study Area}

This study was conducted in four selected districts (Wa Municipality, NadowliKaleo, Jirapa and Wa East Districts) of the Upper West Region of Ghana (Figure 2). The region is located in the Guinea Savannah belt and shares borders with Burkina Faso to the north, Upper East Region to the east, Northern Region to the south and with Côte d'Ivoire to the west (GSS, 2014; GSS, 2013a). The Upper West Region was chosen for this investigation mainly because it has $3.7 \%$ of its population with some form of disability which is more than the national average of 3.0 per cent (GSS, 2012). Though, this region has a number of municipalities and districts, the Wa Municipality, Nadowli-Kaleo, Jirapa and Wa East districts of the Upper West Region were specifically chosen for the study (Figure 2). This was due to the availability of data on people living with disability in these districts. Besides, the rationale for the choice of these districts was to have a large number of respondents and enough data set so as to maximise the quality of the results. 


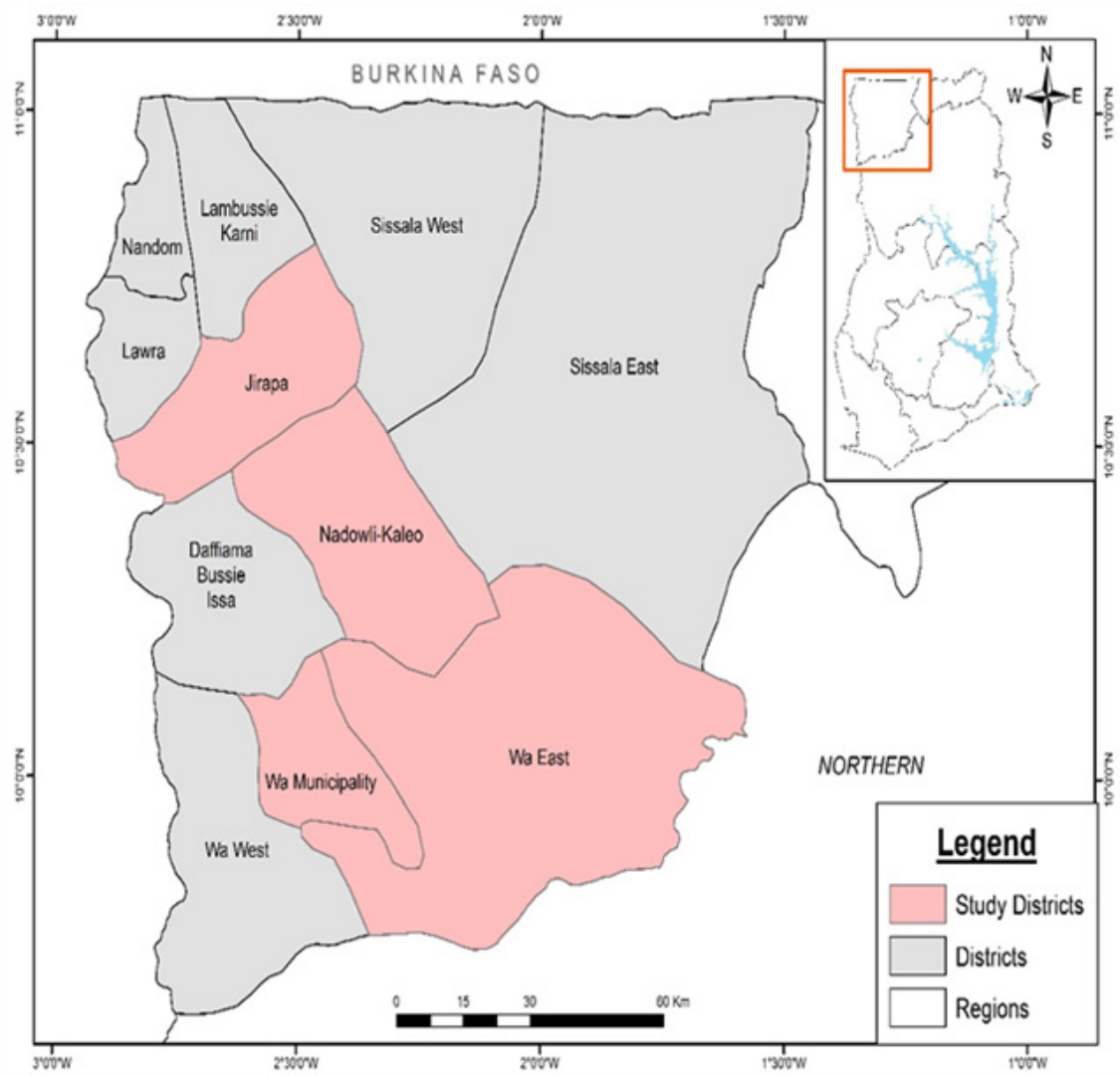

Figure 2: Map of the Upper West Region showing the study Districts

Source: Cartography and Remote Sensing Unit of the Department of Geography and Regional Planning, University of Cape Coast (2016).

\section{Study Design and Population}

The study used a census survey design to examine the PHQOL of older people with disability in selected Districts in the Upper West Region of Ghana (see Figure 2). This survey design is rooted in quantitative methodology which employs standardised measures in data collection, analysis, and hypothesis testing (Bhattacherjee, 2012). The census survey design allowed for the collection of data from many respondents within a short period of time (Creswell, 2012). Moreover, this design permitted the respondents to be interviewed only once (Creswell, 2003).

The study population included older people with visual and physical disability. Among the older people with disability, the study targeted all aged who were 60 
years and older with disability. For this study, older people with disability are those with visual and physical disability. This is in line with the fact that in Ghana, among the population with disability by type, the most common disability is visual, or sight impairment (29.0\%) followed by physical challenges with 18.4 percent (GSS, 2013b). Older people with disability population in the Wa Municipality was 350, NadowliKaleo District was 216, Jirapa District was 200 and that of the Wa East District was 184 , and in all they were 950 which constituted the target population (Wa Municipal Assembly, 2015; Nadowli-Kaleo District Assembly, 2015; Jirapa District Assembly, 2015; Wa East District Assembly, 2015). The total aged population with disability of 950 was obtained from lists of PWDs from the Department of Social Welfare and Community Development in each of the study Districts. A census survey was conducted on the 950 aged with disability owing to the argument in the central limit theorem that a large sample size is more likely to generate a normal distribution in a data set than smaller sample size (Barnett, 1989; Islam, 2018).

\section{Data Collection Instrument}

An interviewer administered questionnaire was used to collect the data. This questionnaire was adapted from the WHOQOL-BREF questionnaire (WHO, 1996; WHO, 2004). The WHOQOL-BREF questionnaire contains three sections. The first section captures socio-demographic characteristics but for the purpose of this study they were adapted from questionnaire of the 2010 Population and Housing Census of Ghana (GSS, 2010). The socio-demographic characteristics consist of gender, age, ethnic group, religious affiliation, marital status, level of education, employment status (Private / Self-employment), type of disability, own biological children, surviving children and living arrangement (GSS, 2010). The adaptation of the socio-demographic characteristics of this questionnaire was to make it suitable in the Ghanaian context. Besides, this adaptation did not alter the consistency and reliability of the instrument in measuring the PHQOL of individuals. The second section of the questionnaire covers the overall QOL and general health (WHO, 1996). Further, the third section has physical health, psychological health, social relations and environmental health QOL domains containing 24 facets (WHO, 1996). However, with respect to this study, the PHQOL domain was adapted and used. It directly indicates the determinants of PHQOL of individuals. This domain has six facets including life enjoyment, meaningfulness of life, concentration, bodily image, selfesteem and negative feelings (WHO, 1996; Gholami et al., 2016). The responses to each of the questions of the facets in this domain were constructed on a 5 -point Likert scale (WHO, 1996). For example: 1 = "Very dissatisfied"; 2 = "Dissatisfied"; 3 $=$ "Neither satisfied nor dissatisfied"; $4=$ "Satisfied" and $5=$ "Very satisfied". This 
is in line with the conceptualization of PHQOL as an objective evaluation which is embedded in cultural, social and environmental context of individuals (WHO, 1996). The instruments were pre-tested in Lawra District (which has similar sociodemographic characteristics as the study areas) before the commencement of the actual data collection.

\section{Data Collection and Analysis}

Prior to the data collection, all protocols regarding community entry were religiously followed. The research team first introduced themselves to officials of the various municipal and district assemblies and the assembly member in each study area was tasked to lead the research team to the chiefs for permission before the commencement of the data collection. During the questionnaire administration, the research team used the home addresses provided on the lists of PWDs to identify the target respondents in each of the study communities. Within a household, the research team first contacted and introduced themselves to the household heads of older people with disability. Second, the household heads upon approval then assisted the research team to seek the consent of the respondents before the questionnaires were administered. To promote understanding and accurate responses, the questions in the instrument (Which were worded in the English Language) were translated by the research team into Wali, Dagaare or Sissali which were the major languages spoken by the respondents. The respondents then provided their responses for the research team to record on the questionnaires. Translation of the questionnaires was deemed necessary because most of the respondents could not read and write in English Language due to illiteracy or effects of their disability. Besides, any respondent who decided not to participate in the study did so without coercion of any kind. Due to death of some of the respondents, incomplete responses, and other ethical reasons, 810 of the questionnaires were processed.

In order to facilitate data entry, the questionnaires were numbered serially. The Statistical Product and Service Solutions (SPSS) version 20 (International Business Machines Corporation [IBM], 2011) was used for the data entry and analysis. The independent variables considered were gender, age, marital status, level of education, type of disability and living arrangement. Gender was men and women. Age was captured in absolute years but was re-coded into three age groups: 60 - 69 years, $70-79$ years, and 80 years and older. Marital status was grouped as never married, married, separated/ divorced, widowed, and other (Specify). Type of disability was visual disability and physical disability. Level of education was 
captured as none, primary, JHS/Middle school, SHS/Vocational/Technical, PostSecondary/Tertiary and other (Specify). However, level of education was collapsed into two broad groups: non-educated and educated. Further, living arrangement was categorised as: alone, nuclear family, extended family and other (Specify) but was collapsed into nuclear and extended families.

Additionally, the dependent variable was PHQOL. The scores in this domain were transformed to a scale ranging from o to 100 to enable comparisons between different domains consisting of unequal numbers of items (WHO, 1996; Cao et al., 2016). In the 5-point Likert scale data, the scores of 1, 2, 3, 4 and 5 were transformed into 20, 40, 60, 80 and 100 respectively (WHO, 1996). Further, the domain mean score was computed by finding the average of all the responses of the facets under it. $A$ lower mean score indicated a lower QOL and higher mean score showed a higher QOL (WHO, 1996; Khan et al., 2014). Moreover, means, independent-samples t-test and one-way Analysis of Variance (ANOVA) statistical tools were used to analyse and report the findings. The use of these tools in the analysis were based on the conditions of a normal distribution and equal variance assumed (Pallant, 2005). The independent-samples t-test was used because it compares two categorical variables in relation to the mean score of continuous variables (Cohen, 1988; Pallant, 2005). It provided the basis for independent variables such as gender, level of education and type of disability to be compared on the mean scores of the PHQOL domain. Again, ANOVA was used because it compares three or more independent variables in relation to the mean scores of continuous variables (Cohen, 1988; Pallant, 2005). Also, independent variables including age and marital status were compared based on the mean scores of the PHQOL domain. In these analyses the effect size was considered. The effect size is the strength of the difference between groups (Cohen, 1988; Pallant, 2005). Besides, in the interpretation of the effect size, Cohen's (1988) classification was used, where 0.2 is considered small effect, 0.5 medium and 0.8 large. In summary, data for this study was extracted from much wider research project conducted in the Upper West Region of Ghana (Nantomah, 2019).

\section{Ethical Issues}

All ethical concerns that govern social sciences research, especially informed consent, confidentiality, and anonymity were strictly adhered. As regards informed consent for instance the rationale of the study was explained to participants before commencing interview. The participants were as well given the opportunity to 
voluntarily participate in the study. Additionally, the findings of the study were not directly linked to the identity of any respondent and no aspect of the information obtained from them was divulged to any third party. Moreover, the study protocol was duly approved by the University of Cape Coast Institutional Review Board (with Ethical Clearance ID No: UCCIRB/CHLS/2016/12) before the fieldwork commenced. Finally, an approval was given by the WHO on the adaptation of the WHOQOL-BREF questionnaire (WHO, 1996).

\section{RESULTS}

\section{Socio-demographic Characteristics of the Older People with Disability}

\section{by Gender}

Table 1 shows percentage distribution of the socio-demographic attributes of the respondents by gender. The results revealed that most of the older people with disability were aged $60-69$ years $(73.8 \%)$ with more women $(74.3 \%)$ than men (73.2\%). Over half (50.9\%) of them were married. However, about 55.2 percent of women as compared to a quarter of men (25.3\%) were widowed. Over two-thirds of them were non-educated (68.6\%). More women (69.6\%) than men (67.4\%) were non-educated. Most of the older people with disability were unemployed (66.7\%). More than half of the respondents had visual disability (52.0\%). Many of them lived in extended family settings (57.0\%). Nevertheless, more men (57.7\%) than women (56.5\%) lived in extended families (Table 1). 
Table 1: Socio-demographic characteristics of the respondents by gender

\begin{tabular}{llll}
\hline Socio-demographic characteristics & $\begin{array}{l}\text { Men } \\
(\mathrm{n}=359)\end{array}$ & $\begin{array}{l}\text { Women } \\
(\mathrm{n}=451)\end{array}$ & $\begin{array}{l}\text { Total } \\
(\mathrm{n}=810)\end{array}$ \\
\hline Age & & & \\
$60-69$ & 73.2 & 74.3 & 73.8 \\
$70-79$ & 24.0 & 22.8 & 23.4 \\
$80+$ & 2.8 & 2.9 & 2.8 \\
Marital status & & & \\
Married & 65.5 & 39.2 & 50.9 \\
Separated/Divorced & 9.2 & 5.6 & 7.1 \\
Widowed & 25.3 & 55.2 & 42.0 \\
Level of education & & & \\
Non-educated & 67.4 & 69.6 & 68.6 \\
Educated & 32.6 & 30.4 & 31.4 \\
Employment status & & & \\
Private / Self employed & 3.6 & 4.7 & 4.2 \\
Unemployed & 69.1 & 64.7 & 66.7 \\
Other & 27.3 & 30.6 & 29.1 \\
Type of disability & & & \\
Visual disability & 54.0 & 50.3 & 52.0 \\
Physical disability & 46.0 & 49.7 & 48.0 \\
Living arrangement & & & \\
Nuclear family & 42.3 & 43.5 & 43.0 \\
Extended family & 57.7 & 56.5 & 57.0 \\
\hline
\end{tabular}

\section{Psychological Health Quality of Life}

The extant literature on ageing and health indicates that background characteristics of older people have significant effect on their PHQOL (Khan et al., 2014; Gholami et al., 2016). To ascertain this claim, this aspect of the study seeks to understand whether the socio-demographic characteristics of the respondents (gender, age, marital status, level of education and type of disability) have any influence on their PHQOL. Table 2 presents the socio-demographic characteristics by PHQOL of older people with disability. Table 2 presents the socio-demographic characteristics by PHQOL of older people with disability. 
Table 2: Socio-demographic characteristics by psychological health QOL of older people with disability

\begin{tabular}{|c|c|c|c|c|c|c|c|c|}
\hline \multirow{3}{*}{$\begin{array}{l}\text { Socio- } \\
\text { demographic } \\
\text { characteristics }\end{array}$} & \multicolumn{8}{|c|}{ Facets of Psychological Health QOL } \\
\hline & \multirow[t]{2}{*}{$\mathbf{N}$} & \multirow{2}{*}{$\begin{array}{l}\text { LE } \\
\text { MS }\end{array}$} & \multirow{2}{*}{$\begin{array}{l}\text { MoL } \\
\text { MS }\end{array}$} & \multirow{2}{*}{$\begin{array}{l}\text { C } \\
\text { MS }\end{array}$} & \multirow{2}{*}{$\begin{array}{l}\text { BI } \\
\text { MS }\end{array}$} & \multirow{2}{*}{$\begin{array}{l}\text { SE } \\
\text { MS }\end{array}$} & \multirow{2}{*}{$\begin{array}{l}\text { NF } \\
\text { MS }\end{array}$} & \multirow{2}{*}{$\begin{array}{l}\text { Overall } \\
\text { PHQOL }\end{array}$} \\
\hline & & & & & & & & \\
\hline \multicolumn{9}{|l|}{ Gender } \\
\hline Men & 359 & 36.4 & 37.9 & 36.4 & 36.6 & 38.7 & 36.9 & 37.2 \\
\hline Women & 451 & 37.2 & 37.2 & 38.1 & 36.2 & 37.7 & 38.5 & 37.5 \\
\hline t-value & & 0.674 & 0.669 & 1.616 & 0.426 & 0.943 & 1.564 & 0.715 \\
\hline P-value & & 0.500 & 0.503 & 0.106 & 0.670 & 0.346 & 0.118 & 0.475 \\
\hline \multicolumn{9}{|l|}{ Age } \\
\hline $60-69$ & 598 & 37.5 & 38.6 & 37.9 & 37.1 & 38.9 & 38.9 & 38.2 \\
\hline $70-79$ & 189 & 35.4 & 34.6 & 35.8 & 35.0 & 36.0 & 35.0 & 35.3 \\
\hline $80+$ & 23 & 30.4 & 33.9 & 36.5 & 27.8 & 34.7 & 32.1 & 32.6 \\
\hline F-value & & 3.719 & 6.339 & 1.507 & 6.121 & 3.402 & 7.122 & 23.872 \\
\hline P-value & & $0.025^{*}$ & $0.002^{*}$ & 0.222 & $0.002 *$ & $0.034 *$ & $0.001 *$ & $0.000^{* * *}$ \\
\hline \multicolumn{9}{|l|}{ Marital status } \\
\hline Married & 412 & 38.7 & 39.7 & 39.4 & 38.5 & 39.7 & 39.3 & 39.2 \\
\hline \multicolumn{9}{|l|}{ Separated/ } \\
\hline Divorced & 58 & 33.1 & 34.1 & 33.4 & 34.8 & 38.2 & 36.9 & 35.1 \\
\hline Widowed & 340 & 35.2 & 35.4 & 35.5 & 34.1 & 36.2 & 36.1 & 35.5 \\
\hline F-value & & 7.075 & 10.057 & 9.302 & 9.254 & 5.075 & 4.555 & 42.690 \\
\hline P-value & & $0.001^{* *}$ & $0.000 * *$ & $0.000^{* * *}$ & $0.000^{* *}$ & $0.006^{* *}$ & $0.011^{* *}$ & $0.000^{* * *}$ \\
\hline \multicolumn{9}{|l|}{$\begin{array}{l}\text { Level of } \\
\text { Education }\end{array}$} \\
\hline Non-educated & 556 & 37.7 & 37.6 & 36.8 & 37.0 & 37.8 & 38.2 & 37.5 \\
\hline Educated & 254 & 34.9 & 37.4 & 38.7 & 35.0 & 38.9 & 37.0 & 37.0 \\
\hline t-value & & 2.475 & 0.204 & 1.783 & 1.879 & 1.051 & 1.088 & 1.117 \\
\hline P-value & & $0.014^{*}$ & 0.839 & 0.075 & 0.061 & 0.293 & 0.277 & 0.264 \\
\hline \multicolumn{9}{|l|}{ Type of disability } \\
\hline Visual disability & 421 & 35.2 & 37.8 & 36.3 & 36.2 & 37.0 & 37.1 & 36.6 \\
\hline Physical disability & 389 & 38.6 & 37.2 & 38.5 & 36.6 & 39.4 & 38.5 & 38.1 \\
\hline t-value & & 3.266 & 0.529 & 2.097 & 0.461 & 2.360 & 1.388 & 3.609 \\
\hline P-value & & $0.001^{* * *}$ & 0.597 & $0.036^{*}$ & 0.645 & $0.019^{*}$ & 0.166 & $0.000^{* *}$ \\
\hline
\end{tabular}

Generally, slight differences were found in mean scores between men (37.2) and women (37.5). Statistically, no significant difference [t $(808)=0.715, p=0.475]$ was ascertained in PHQOL and gender of the respondents, such that the men had a mean score $(M=37.2 ; S D=6.22)$ and the women $(M=37.5 ; S D=6.11)$. The magnitude 
of the differences in the means between men and women was very small (eta $\mathrm{sq}=$ o.00).

Table 2 also reveals that mean scores in PHQOL was highest among those who were aged 60-69 years (38.2) and lowest for those who were aged 80 years and older (32.6). Further analysis using a one-way ANOVA revealed a statistically significant difference $[F(807)=23.872$ value, $p=0.000]$ between PHQOL and age. For instance, those who were aged $60-69$ years had a mean score $(M=38.2 ; S D=6.76), 70-79$ years $(M=35.3 ; S D=7.40)$ and 80 years and older $(M=32.6 ; S D=5.89)$. The significant difference observed across the age of the respondents was medium (eta $\mathrm{sq}=0.08$ ).

As observed in Table 2, mean scores in PHQOL was highest among those who were married (39.2) and lowest for those who were separated / divorced (35.1). A one-way ANOVA was conducted to assess the impact of marital status on PHQOL of the older people with disability. The analysis disclosed that significant difference $[\mathrm{F}(807)=$ 42.690 value, $p=0.000$ ] was noticed with regard to PHQOL across marital statuses, such that those married had a mean score $(M=39.2 ; S D=4.76)$, separated/divorced $(M=35.1 ; S D=6.40)$ and widowed $(M=35.5 ; S D=6.89)$. The differences observed above, however, indicated a medium effect size (eta $\mathrm{sq}=0.10$ ).

The results further show that the mean score in PHQOL was higher for those with physical disability (38.1) than those with visual disability (36.6). An independentsamples t-test was also conducted to evaluate the PHQOL of the older people with physical and visual disability. The analysis revealed a significant difference [t (808) = 3.609, $p=0.000$ ] in PHQOL between type of disability, such that those with physical disability had a mean score $(M=38.1 ; S D=5.93)$ and those with visual disability ( $M$ $=36.6 ; \mathrm{SD}=6.27)$. The degree of the differences in the means between those with physical disability and visual disability was very small (eta $\mathrm{sq}=0.01$ ).

\section{DISCUSSION}

Through a census survey, this study examined the PHQOL of older people with disability in selected Districts in the Upper West Region of Ghana (Wa Municipality, Nadowli-Kaleo, Jirapa and Wa East Districts) using an interviewer administered questionnaire. Means, independent-samples t-test and one-way Analysis of Variance (ANOVA) statistical tools were used to analyse the data and report the findings. The study revealed that mean scores in PHQOL of the respondents were generally low for both men and women. These revelations contradict what Dongre and Deshmukh (2012) found in their study where the mean scores of perceived 
PHQOL was significantly higher among aged men than women. The current findings are further at variance with what Cheraghi, et al. (2016) observed in their study that aged men had a better status in the psychological domain in relation to aged women. The plausible reason why mean scores in PHQOL of the older people with disability were generally low could be associated with the adverse effect of the obstacles and difficulties they encounter in the performance of their daily activities (Čanković et al., 2016).

There are studies which have reported highest PHQOL among older people who are aged 60-69 years as compared to those aged 70-79 years and 80 years and older (Datta et al., 2015; Cheraghi, et al., 2016). Similarly, this study discovered that mean scores in PHQOL was highest among those who were aged 60-69 years and lowest for those who were aged 80 years and older. These results suggest that respondents who were aged 60-69 years had the highest PHQOL in relation to those who were aged 70-79 years and 80 years and older. This evidence supports the postulation that PHQOL becomes poorer with the advancement of age (Datta et al., 2015). In addition, the results from Table 2 resonate with the adapted ICF framework for the study that age is a determinant of PHQOL of the aged with disability (WHO, 1996; WHO, 2001).

Family support contributes positively to the PHQOL of older people (Kaur et al., 2015). To better project the importance of family support to the aged, the hierarchical compensatory model hypothesises that older people are more likely to seek support first from spouses, next from adult children, then from other relatives and friends and finally from formal services (Cantor, 1979; Armi et al., 2008). In this study, mean scores in PHQOL was highest among those who were married and lowest among those who were separated / divorced (Table 2). This finding suggests that older people who were married had the highest PHQOL compared with those who were separated / divorced and widowed. Further evidence from Table 2 confirms the ICF framework adapted for the study which argues that marital status is a fundamental determinant of PHQOL of an individual (WHO, 1996; WHO, 2001). Perhaps, the availability of a spouse could help improve the PHQOL of a married aged with disability than his or her counterpart who has no partner (Kaur et al., 2015).

The experiences with disability vary from one person to the other, hence; differences exist in PHQOL of individuals (WHO, 2001; GSS, 2013b). Accordingly, this study has shown that the mean score in PHQOL was higher for those with physical disability than those with visual disability. These results were expected because 
the influence of vision loss on activity limitations is one possible mechanism that reduces PHQOL of older people (Brown \& Barrett, 2011).

\section{CONCLUSIONS AND IMPLICATIONS}

Ensuing from the key findings of the study, the following conclusions were distilled: Older people with disability irrespective of their gender had low PHQOL. Notwithstanding this, PHQOL was highest among those aged 60-69 years and lowest for those aged 80 years and older. Respondents who were married had the highest PHQOL compared with those who were separated / divorced and widowed. Psychological health QOL was equally higher for those with physical disability than those with visual disability.

The study recommends for the Department of Social Welfare and Community Development of the Metropolitan, Municipal and District Assemblies in Ghana including benevolent organisations and individuals to organise geriatric interventions including free education, companionship, counselling, relaxation therapy and home-based health care for older people with disability especially those aged 80 years and older, the separated / divorced and widowed, and those with visual disability in order to improve upon their PHQOL. One major contribution of this study which must be highlighted is that it is among the first to have used the International Classification of Functioning, Disability and Health (ICF) framework to understand the PHQOL of older people, especially from a developing country context like Ghana. However, it is important to state that this study was limited to some selected districts in the Upper West region, therefore, extrapolations of the findings should be done with caution. Finally, based on the general evidence, this study concludes that future academic inquisitions aiming to understand contemporary issues on the PHQOL of older people with disability ought not preclude the critical role of their background characteristics as epitomized in the conceptual framework of the study (Figure 1).

REFERENCES

Abdel-Khalek, A. M. (2016). Introduction to the psychology of self-esteem. Nova Science Publishers, Inc. New York.

Armi, F., Guilley, E., \& Lalived'Epinay, C., J. (2008). The interface between formal and informal support in advanced old age: A ten-year study. International Journal of Ageing and Later Life, 3(1), 5-19. 
Aydos, S. (2012). Telomeres and reproductive aging. INTECH Open Access Publisher.

Ayernor, P. K. (2012). Diseases of ageing in Ghana. Ghana Medical Journal, 46(2), 18-22.

Bailey, K. A., Gammagea, K. L., \& van Ingena, C. (2017). How do you define body image? Exploring conceptual gaps in understandings of body image at an exercise facility. Body Image, 23, 69-79.

Barnett, N., S. (1989). A central limit theorem for assessing average quality. International Journal of Quality \& Reliability Management, 6(4), 0265$671 X$.

Ba-Ama, E., \& YaabaAckah, P. (2014). Causes of neglect of the aged in Sekondi -Takoradi metropolis, Ghana. International Research Journal of Arts and social Science 3(1), 8-16.

Bhattacherjee, A. (2012). Social science research: Principles, methods, and practices ( $2^{\text {nd }}$ ed.). Florida, USA, University of South Florida.

Braithwaite, J., \& Mont, D. (2009). Disability and poverty: A survey of world bank poverty assessments and implications. ALTER-European Journal of Disability Research, 3, 219-232.

Brown, R., L., \& Barrett, A., E. (2011). Visual impairment and quality of life among older adults: An examination of explanations for the relationship. The Journals of Gerontology, Series B: Psychological Sciences and Social Sciences, 66(3), 364-373.

Čanković, S., Ač-Nikolić, E., Mijatović-Jovanović, V., Kvrgić, S., Harhaji, S., \& Radić, I. (2016). Quality of life of elderly people living in a retirement home. Vojnosanitetski pregled, 73(1), 42-46.

Cantor, M., H. (1979). Neighbors and friends: An overlooked resource in the informal support system. Research on Aging, 1(4), 434-463.

Cao, W., Guo, C., Ping, W., Tan, Z., Guo, Y., \& Zheng, J. (2016). A community-based study of quality of life and depression among older adults. International Journal of Environmental Research and Public Health, 13, 1-10.

Cartography and Remote Sensing Unit of the Department of Geography and Regional Planning, University of Cape Coast (September, 2016). Map of the upper west region showing study districts. University of Cape Coast (Unpublished). 
Castañer, M., Torrents, C., Anguera, M. T., Dinušová, M., \& Jonsson, G. K. (2009). Identifying and analyzing motor skill responses in body movement and dance. Behavior Research Methods, 41(3), 857-867.

Cheraghi, Z., Doosti-Irani, A., Nedjat, S., Cheraghi, P., \& Nedjat, S. (2016). Quality of life in elderly Iranian population using the QOL-Brief questionnaire: A systematic review. Iranian Journal of Public Health, 45(8), 978-985.

Clarke, P. \& Nieuwenhuijsen, E. R. (2009). Environments for healthy ageing: A critical review. Maturitas, 64(1), 14-19.

Cohen, J. (1988). Statistical power analysis for the behavioral sciences. Hillsdale, $\mathrm{NJ}$ : Erlbaum.

Creswell, J. W. (2012). Educational research: Planning, conducting, and evaluating quantitative and qualitative research $\left(4^{\text {th }}\right.$ ed.). Boston: Pearson Education Inc.

Creswell, J. W. (2003). Research design: Qualitative, quantitative and mixed methods approaches ( $2^{\text {nd }}$ ed.), California: Sage Publications Inc.

Cutler, D. M., Wise, D., A. \& Woodbury, R., G. (2009). Introduction to "health at older ages: The causes and consequences of declining disability among the elderly. In Health at Older Ages: The Causes and Consequences of Declining Disability among the Elderly. University of Chicago Press, 1-18.

Damasio, F.B., de Melo, R.L.P., \& da Silva, J.P. (2013). Meaning in life, psychological well-being and quality of life in teachers, Paidéia, 23(54), 73-82.

Datta, D., Datta, P., P., \& Majumdar, K. K. (2015). Association of quality of life of urban elderly with socio-demographic factors. International Journal of Medicine and Public Health, 5(4), 274-278.

Davidson, G., Irvine, R., Corman, M., Kee, F., Kelly, B., Leavey, G., \& McNamee, C. (2017). Measuring the Quality of Life of People with Disabilities and their Families: Scoping Study Final Report. Department for Communities. Retrieved from https://www.communities-ni.gov.uk/publications

Diener, E., \& Suh, E. (1997). Measuring quality of life: Economic, social, and subjective indicators. Social Indicators Research, 40, 189-216.

Dongre, A. R., \& Deshmukh, P., R. (2012). Social determinants of quality of elderly life in a rural setting of India. Indian Journal of Palliative Care, 18(3), 181-189.

Dubey, A., Bhasin, S., Gupta, N., \& Sharma, N. (2011). A study of elderly living in old age home and within family set-up in Jammu. Studies on Home and Community Science, 5 (2), 93-98. 
Ghana Statistical Service (2014). 2010 Population \& housing census: District analytical report: Wa municipality. Accra: Ghana Statistical Service.

Ghana Statistical Service (2013a). 2010 population \& housing census: Regional analytical report: Upper west region. Accra: Ghana Statistical Service.

Ghana Statistical Service (2013b). 2010 Population \& housing census report: The elderly in Ghana. Accra: Ghana Statistical Service.

Ghana Statistical Service (2012). 2010 Population \& housing census; Summary report of final results. Accra: Ghana Statistical Service.

Ghana Statistical Service (2010). 2010 population and housing census: You count. So get counted! Accra, Ghana: Ghana Statistical Service.

Gholami, A., Araghi, M. T., Shamsabadi, F., Bayat, M., Dabirkhani, F., Moradpour, F., Mansori, K., Moradi, Y., \& Rajabi, A. (2016). Application of the world health organization quality of life instrument, short form (WHOQOLBREF) to patients with cataract. Epidemiology and Health, 38, 1-7.

Giddens, A., Duneier, M., \& Appelbaum, R. (2005). Introduction to sociology ( $5^{\text {th }}$ ed.). New York: W.W. Norton \& Company Inc.

Goldberg, D. P., Gater, R., Sartorius, N., Ustun, T. B., Piccinelli, M., Gureje, O., Rutter, C. (1997). The validity of two versions of the GHQ in the WHO study of mental illness in general health care. Psychological Medicine, 27(1), 191-197.

Gómez, M. M. N., Gutiérrez, R. M. V., Castellanos, S. A. O., Vergara, M. P., Pradilla, Y. K. R. (2010). Psychological well-being and quality of life in patients treated for thyroid cancer after surgery. Terapia Psicológica, 28(1), 69-84.

Grewal, D. S. (2014). Improving concentration and mindfulness in learning through meditation. Journal of Humanities and Social Science (IOSRJHSS), 19(2), 33-39.

Hayflick, L. \& Moorehead, P.S. (1980). The cell biology of human aging. Scientific American, 242, 58-66.

HelpAge International (2004). Practical issues in ageing and development (Ageways Working Paper No. 64). Retrieved from http:// www.helpage. org

International Business Machines Corporation (2011). The international business machines (IBM) corporation statistical product and service solutions (SPSS) statistics data editor. Retrieved from http://www.ibm.com/ support 
Islam, R. M. (2018). Sample Size and its role in central limit theorem (CLT). Computational and Applied Mathematics Journal, 4(1), 1-7.

Jin, K. (2010). Modern biological theories of aging. Aging and Disease, 1(2), 72-74.

Jirapa District Assembly (2015). Submission of PWD update list. Jirapa District Assembly: Department of Social Welfare and Community Development (Unpublished).

Jongbloed, L. (2003). Disability policy in Canada: An overview. Journal of Disability Policy Studies, 13(4), 203-209.

Kaur, H., Kaur, H., \& Venkateashan, M. (2015). Factors determining family support and quality of life of elderly population. International Journal of Medical Science and Public Health, 4(8), 1049 -1053.

Kerce, E. W. (1992). Quality of life: Meaning, measurement, and models. San Diego CA: Navy Personnel Research and Development Center.

Khan, M. N., Mondal, M. N. I., Hoque, N., Islam, M. S., \& Shahiduzzaman, M. (2014). A study on quality of life of elderly population in Bangladesh. American Journal of Health Research, 2(4), 152-157.

Kinsella, K., \& Phillips, D. R. (2005). Global aging: The challenge of success. Population Bulletin, 60(1).

Mann, W. C. (2004). The aging population and its needs. Pervasive Computing, Institute of Electrical and Electronics Engineers, 3(2), 12-14.

Mba, C., J. (2007). Population ageing in Ghana and correlates of support availability. Gerontechnology, 6(2), 102-111.

Murphy, K., O'Shea, E., Cooney, A., \& Casey, D. (2008). The quality of life of older people with a disability in Ireland. National Council on Ageing and Older People. Retrieved from http://www.ncaop.ie/publications

Nadowli-Kaleo District Assembly (2015). Database on persons with disabilities in Nadowli-Kaleo District. Nadowli-Kaleo District Assembly: Department of Social Welfare and Community Development (Unpublished).

Nantomah, B. (2019). Perceived Quality of Life of The Aged with Disability in Selected Districts in the Upper West Region of Ghana. Thesis submitted to the Department of Population and Health of the Faculty of Social Sciences, College of Humanities and Legal Studies, University of Cape Coast (Unpublished). 
Pallant, J. (2005). SPSS survival manual: A step by step guide to using SPSS for windows (version 12). New South Wales: Allen \& Unwin.

Putnam, M. (2002). Linking aging theory and disability models: Increasing the potential to explore aging with physical impairment. The Gerontologist,42(6),799-806.

Saleeby, P., W. (2007). Applications of a capability approach to disability and the international classification of functioning, disability and health (ICF) in social work practice. Journal of Social Work in Disability \& Rehabilitation, 6(1), 217-232.

Schalock, R., L. (2004). The emerging disability paradigm and its implications for policy and practice. Journal of Disability Policy Studies, 14(4), 204-215.

Schalock, R. L., Brown, I., Brown, R., Cummins, R., A., Felce, D., Matikka, L., \& Parmenter, T. (2002). Conceptualization, measurement, and application of quality of life for persons with intellectual disabilities: Report of an international panel of experts. American Association on Mental Retardation, 40(6), 457-470.

Smith, A. (2000). Researching quality of life of older people: Concepts, measures and findings. Centre for Social Gerontology Working Paper, 7.

Travability (2011). An economic model of disability. Travability Occasional Paper, 4. Retrieved from http:// www.travability.travel

Tripathi, R., K. (2012). Quality of life: An important issue in geriatric research. Journal of Gerontology and Geriatric Research, 1(5), 1-2.

Tsakiri, L. T. (2010). Is globalisation affecting the quality of life? A review of the literature. European Research Studies Journal, 13(4), 157-168.

Velkoff, V., A., \& Kowal, P., R. (2007). Population aging in Sub-Saharan Africa: Demographic dimensions 2006. US Department of Commerce, Economics and Statistics Administration, US Census Bureau, 7(1).

Wa East District Assembly (2015). Wa east district persons with disabilities database. Wa East District Assembly, Department of Social Welfare and Community Development (Unpublished).

Wa Municipal Assembly (2015). Wa municipal assembly database - PWD. Wa Municipal Assembly: Department of Social Welfare and Community Development (Unpublished).

Weeks, J. R. (1999). Population; An introduction to concepts and issues ( $7^{\text {th }}$ ed.). Belmont CA: Wadsworth Publishing Company. 
World Health Organization (2014a). Ghana country assessment report on ageing and health. Geneva: World Health Organization.

World Health Organization (2014b). Visual impairment and blindness, Fact sheet number 282, Geneva, Switzerland: World Health Organization.

World Health Organization (2013). How to use the ICF: A practical manual for using the international classification of functioning, disability and health (ICF). Exposure draft for comment. Geneva: World Health Organization.

World Health Organization (2011). World report on disability. Geneva: World Health Organization.

World Health Organization (2004). The world health organization quality of life (WHOQOL) -BREF. Geneva: World Health Organization.

World Health Organization (2002a). Towards a common language for functioning,

disability and health: International classification of functioning, disability and health. Geneva: World Health Organization.

World Health Organization (2002b). Active ageing: A policy framework. Geneva: World Health Organization.

World Health Organization (2001). International classification of functioning, disability and health (ICF). Geneva: World Health Organization.

World Health Organization (1996). WHOQOL-BREF: Introduction, administration, scoring and generic version of the assessment-Field trial version. Programme on mental health. Geneva: World Health Organization.

World Health Organization Quality of Life Group (1997). The world health organization quality of life assessment (WHOQOL): Measuring quality of life. Geneva: World Health Organization. 